\title{
A política de cotas raciais no Brasil segundo a percepção de negros de camadas médias do Rio de Janeiro
}

\author{
Samara Mancebo Lerner \\ Doutora em Ciências Sociais (Universidade Estadual do Rio de Janeiro) \\ Professora do Departamento de Ciências Sociais da PUC-Rio \\ Rio de Janeiro, Rio de Janeiro, Brasil \\ samaramancebo@gmail.com
}

O debate sobre a adoção de políticas de cotas raciais no ensino superior vem dividindo opiniões no Brasil e apresentando dois bem marcados discursos: um em favor das cotas, defendendo a diversidade cultural e a democratização do ensino superior; e outro que se posiciona em defesa da manutenção de políticas universalistas, argumentando que a adoção das cotas raciais ferem nossa tradição de mestiçagem e fomentaria a racialização da sociedade. $\mathrm{O}$ interesse deste artigo está em contribuir para a discussão sobre relações raciais no Brasil, a partir da análise da percepção de profissionais negros de camadas médias do Rio de Janeiro sobre a adoção de tais políticas no ensino superior e de suas justificativas para apoiá-las ou recusá-las. Utilizarei dados de pesquisas recentes sobre ações afirmativas (AA) raciais no Brasil e entrevistas semiestruturadas com negros de classe média, no Rio de Janeiro.

Palavras-chave: ação afirmativa, política de cotas raciais, relações raciais, educação superior, desigualdades de oportunidades educacionais.

\section{Apresentando o estudo e sua metodologia}

$\mathrm{O}$ debate sobre a adoção de políticas de ação afirmativa (AA) no ensino superior público, sobretudo aquelas racialmente orientadas, vem, desde a última década, dividindo opiniões no Brasil. O debate acadêmico tem apresentado dois bem marcados discursos: um em favor das AA raciais, defendendo a diversidade cultural nas universidades e a democratização do ensino superior; e outro, contrário, que se posiciona em defesa da manutenção de políticas universalistas, argumentando que as AA raciais ferem nossa tradição de mestiçagem e trarão como consequência a racialização da sociedade. Este artigo se posiciona dentro desse campo de estudos e debate com o objetivo de contribuir para a discussão sobre relações raciais no Brasil, a partir da análise da percepção de profissionais negros de camadas médias do Rio de Janeiro sobre a adoção de tais políticas no ensino superior e de suas justificativas para apoiá-las ou recusá-las. Utilizarei dados de pesquisas recentes sobre AA raciais ${ }^{1}$

1. Neste estudo, compreendo ações afirmativas como um conjunto de medidas que visam alocar bens para grupos específicos, discriminados pela exclusão socioeconômica e/ou cultural, como as definem Feres Jr. e Zoninsein (2006, apud Daflon et al., 2013). Dentre as modalidades de ação afirmativa adotadas no Brasil, a política de cotas é a modalidade mais comum, sendo adotada por cerca de metade das universidades públicas que desenvolvem ações afirmativas no país (Daflon et al., 2013). O próprio debate sobre as ações afirmativas no Brasil tem girado em torno da implementação das cotas. Desse modo, este trabalho 
no Brasil e entrevistas semiestruturadas com negros de classe média, ${ }^{2}$ no Rio de Janeiro.

Sendo os negros o objeto das referidas políticas de Ação Afirmativa raciais, conhecer o que pensa um grupo de 80 negros sobre tais políticas e os repertórios que elencam para justificar sua aprovação ou resistência a elas contribui para melhor compreendermos nossa realidade, as relações raciais que a atravessam e as possíveis ambiguidades que permeiam nosso imaginário social quando abordamos a questão do racismo, das desigualdades e discriminação raciais no Brasil. Além disso, ao assumir como foco de minha análise a percepção de (80) negros de camadas médias, tomo como objetivo tecer possíveis correlações entre valores e a posição social dos entrevistados. Pesquisas recentes, como a realizada pelo Datafolha (2008), por exemplo, demonstram que indivíduos com maior renda e escolaridade tendem a ser contrários às políticas de cotas racialmente orientadas. Focar a percepção de um grupo específico de negros - o de profissionais de camadas médias - ajudará a iluminar os valores que exercem maior influência sobre seus repertórios, as lentes através das quais os entrevistados percebem os negros e as políticas educacionais para sua inclusão no ensino superior, e em que medida suas percepções se relacionam com os resultados dos referidos surveys nacionais.

Neste artigo, analisarei a percepção de 80 profissionais negros, de camadas médias do Rio de Janeiro, sobre as políticas de cotas focalizadas para negros, em universidades públicas brasileiras. Findada esta primeira parte, em que apresento o estudo e sua metodologia, focarei alguns trabalhos que me permitirão lançar luz sobre as desigualdades de oportunidades educacionais que cortam as trajetórias de mobilidade social de negros no Brasil. O mapeamento desse cenário será de grande valia para a compreensão das justificativas dos entrevistados sobre a implantação de políticas de cotas raciais no ensino superior. Feito isso, abordarei a percepção dos entrevistados sobre a implantação das referidas políticas, destacando os repertórios utilizados por eles para justificar sua posição favorável ou contrária às mesmas. Minha intenção, portanto, é poder observar em que medida suas percepções dialogam com as pesquisas nacionais e mapear as divergências e convergências de seus repertórios em relação ao debate acadêmico sobre as cotas raciais - sem deixar de atentar para as ambiguidades contidas nesses repertórios, as quais os dados qualitativos me habilitam apreender. Com isso, pretendo contribuir para a reflexão sobre as relações raciais no Brasil e os valores envolvidos na forma como as concebemos. O estudo das percepções, neste caso, mostra-se apropriado, tendo em vista que possibilita, como já salientaram Silva e Reis (2011), capturar cognições (entendimentos não valorativos), normas (ideias internalizadas sobre regras apropriadas) e valores (ideais sobre o que deve ser).

As entrevistas analisadas neste artigo provêm do projeto "A Comparative Study of Responses to Discrimination by Members of Stigmatized Groups", da Universidade de Harvard, desenvolvido em parceria com o Núcleo Interdisciplinar de Estudos sobre Desigualdade (NIED) da Universidade Federal do Rio de Janeiro (Lamont; Mizrachi, 2012; Silva, 2012; Silva; Reis, 2012). As entrevistas foram realizadas no Brasil, EUA e Israel, entre 2007 e 2009, e em cada um dos referidos países foram realizadas aproximadamente 150 entrevistas em profundidade com grupos estigmatizados, de ambos os sexos, pertencentes a distintas classes sociais. Neste artigo, como já referi, focarei o grupo de 80 profissionais negros pertencentes à classe média carioca.

Durante as entrevistas, que levaram em média duas horas cada uma, os entrevistados foram questionados sobre uma gama de temas relativos à questão racial no Brasil, dentre os quais, seu conhecimento e opinião sobre políticas de ação afirmativa e, mais especificamente, sobre a modalidade de cotas para negros no ensino superior. Além das perguntas diretas sobre o tema, outras que envolviam a questão das desigualdades e discriminação raciais no Brasil abriram caminho para menção espontânea ao tema das cotas e permitiram a elaboração deste artigo.

A seleção dos casos obedeceu aos seguintes critérios: ser composta por homens (40) e mulheres (40); os entrevistados deveriam se identificar como pretos ou pardos (segundo codificação do IBGE) $;^{3}$ ter entre 25 e 60 anos; ser graduados em profissões de prestígio como direito, engenharia, medicina, jornalismo etc.; estar trabalhando, no momento da entrevista, em ocupações de prestígio e em áreas econômicas tradicionais (saúde, serviço público, bancos, telecomunicações etc.) da cidade do Rio de Janeiro. A escolha do Rio de Janeiro para seleção dos casos, como afirmam Silva e Reis (2011), se deve à importância da cidade para os propósitos da pesquisa. Sendo uma grande metrópole, conta com grandes empresas públicas e

tomará como sinônimos "ações afirmativas (AA) raciais" e "cotas raciais" para ingresso de pretos e pardos na educação superior.

2. A identificação dos entrevistados com pertencentes a uma classe média, na pesquisa, obedeceu à sua formação e atuação profissional Considerou-se como pertencente à classe média o entrevistado que fosse graduado em profissões de prestígio, como direito, engenharia, medicina, economia e jornalismo, por exemplo, e que estivesse trabalhando, no momento da entrevista, em ocupações de prestígio e em áreas econômicas tradicionais, como saúde, serviço público, bancos, telecomunicações etc.

3. Os entrevistados foram confrontados com duas questões raciais: uma dada livremente pelos entrevistados (autoidentificação), outra dada por eles com base nas categorias oficiais do IBGE (preto, pardo, branco, indígena, amarelo). 
privadas, nas mais variadas áreas de ocupação e, sobretudo, naquelas tradicionais que são do interesse do estudo. O Rio de Janeiro é também a metrópole com maior percentual de negros do país, favorecendo, por sua vez, a seleção de profissionais negros ocupados em postos de prestígio, em áreas econômicas tradicionais da cidade. Somado a isso, a cidade do Rio de Janeiro foi a primeira, no Brasil, a abrigar o sistema de cotas raciais para ingresso na universidade. Por um lado, é preciso salientar que a opção por essa cidade torna a pesquisa - e este estudo que desenvolvo a partir dela - não representativa do universo nacional, o que limita generalizações. Por outro lado, torna possível estabelecer correlações importantes para se pensar as relações raciais no Brasil.

Para a seleção dos referidos casos, foi utilizada a amostragem por bola de neve, que diz respeito à prática de pedir aos entrevistados que recomendem outros respondentes ao pesquisador. Como qualquer técnica de pesquisa, o uso da bola de neve traz benefícios e limitações. Se, por um lado, seu uso possibilita o aumento do número de entrevistados - visto que, ao serem indicados por amigos, se sentem mais à vontade para participar da pesquisa -, por outro, os entrevistados são mais propensos a construir uma rede social ao final da pesquisa do que se tivessem sido selecionados por amostragem aleatória (Small, 2009). Outra limitação relativa à sequência de casos, especificamente, refere-se à falta de dados sobre profissionais negros no Brasil. Como resultado dessa ausência, os primeiros entrevistados não pertenciam ao público-alvo da pesquisa, sendo professores universitários e assistentes sociais, para citar alguns profissionais. A partir de então, cada um dos entrevistados referenciou até outros dois respondentes identificados por eles como negros.

Entre os profissionais entrevistados estão homens e mulheres economistas, contadores, analistas de sistemas, médicos, enfermeiros, fonoaudiólogos, assistentes sociais, engenheiros, advogados, psicólogos, jornalistas, comunicadores, professores universitários, pesquisadores, bibliotecários, militares, guias turísticos, e funcionários públicos de várias categorias. Todos se definiram como pardos ou pretos - quando diante dos códigos do IBGE -, e 64 dos 80 entrevistados identificaram-se espontaneamente como negros. Os demais definiram-se como pretos, pardos, mulatos, morenos ou preferiram não se definir.

Sendo o grupo de entrevistados composto por negros (objeto de tais políticas) com nível superior de ensino e que atuam em ocupações de prestígio no Rio de Janeiro, pressuponho que os mesmos já transpuseram uma série de obstáculos até ocuparem as posições sociais e econômicas em que se encontram. Desse modo, argumento que suas percepções, apesar de não representativas do universo nacional, lançarão novos dados para pensarmos as relações raciais brasileiras e uma das formas de enfrentamento das desigualdades e discriminação raciais adotadas no Brasil na contemporaneidade - as ações afirmativas raciais, em sua modalidade de cotas para negros no ensino superior.

\section{Desvantagens cumulativas, desigualdades duráveis: as interseções entre desigualdade racial e educacional no Brasil}

Em Relatório anual das desigualdades raciais no Brasil, Marcelo Paixão et al. (2011) argumentam que, nos últimos anos, a desigualdade entre brancos e negros sofreu relativa diminuição, podendo ser expressa em um aumento, entre estes últimos, da renda média do trabalho, da média de anos de estudos, da esperança de vida ao nascer; e, por outro lado, na diminuição da taxa de pobreza e indigência, da mortalidade materna e infantil etc. Fatores como o controle da inflação, o aumento real do salário mínimo, o aumento da escolaridade, assim como a expansão das políticas de transferência de renda, estariam intimamente ligados à redução das assimetrias inter-raciais nas últimas décadas. Dados como esses não indicam, no entanto, que estaríamos em via de superar as desigualdades históricas entre brancos e negros, tampouco que políticas estratégicas para o combate às desigualdades inter-raciais perderam o sentido e importância na atualidade (Paixão et al., 2011). Dados da Pesquisa Nacional por Amostra de Domicílio (PNAD, 2003, 2013) comprovam o argumento de Paixão et al. (2011), atestando, contudo, a persistência de significativa desigualdade entre brancos e negros ${ }^{4}$ no acesso a serviços sociais - tais como educação -, a ocupações de maior remuneração, assim como a predominância dos negros entre os grupos mais pobres da população. Para ilustrar esse cenário, lançarei mão de alguns dados da própria PNAD.

Ao observar a distribuição da população por quintos de rendimento mensal familiar, segundo sua cor/raça, nota-se pequena mudança entre 2002 e 2012 (PNAD, 2003, 2013). Em 2002, 28,1\% dos negros encontravam-se no primeiro quintil de renda, contra 13,0\% dos brancos. A situação se inverte

4. Cabe ressaltar que a PNAD e demais pesquisas do IBGE não usam a categoria Negro, mas sim, pretos e pardos. Ao usar o termo "negro" compreendo, portanto, a população de pretos e pardos descrita pelo IBGE e intento marcar mais claramente as desigualdades entre brancos e não brancos no país. 
no último quintil quando constatamos a presença de apenas $10,4 \%$ dos negros, contra $28,1 \%$ dos brancos. Dez anos mais tarde, observa-se pequena diferenciação neste cenário, visto que $27,3 \%$ dos negros ainda compõem o primeiro quintil de renda e apenas $11,6 \%$ deles o último. Reforçando a lógica já denunciada por Hasenbalg e Silva (2003), os negros continuam sendo maioria nos estratos mais baixos da população e seu número tende a diminuir conforme aumentam os quintis de rendimentos. Isto é, a pobreza no Brasil continua apresentando clara demarcação racial e as trajetórias de mobilidade ascendente de negros ainda encontram barreiras a serem transpostas, entre as quais o acesso diferenciado à educação.

No campo educacional, apesar de sua notável expansão nas últimas décadas, a PNAD (2013) nos mostra que a taxa de analfabetismo dos negros de 15 anos ou mais de idade, embora tenha diminuído de 17,3\% para 11,8\% entre 2002 e 2012, ainda permanece expressiva e superior a dos brancos, cujo percentual de analfabetos em 2002 era 7,5\%, tendo baixado para 5,3\% em 2012. A média de anos de estudo da população negra, como apontaram Paixão et al. (2011), de fato aumentou nos últimos anos (de 4,9 para 6,7 anos), mas, apesar disso, ainda se mostra menor do que a média de anos de estudo dos brancos - que aumentou de 7,0 para 8,6 - e a própria média nacional que, em 2012, ficou em 7,6 anos de estudo.

O acesso aos sistemas público e privado de educação, no ensino básico e superior, também apresenta diferenciações segundo cor/raça. Não obstante sejam maioria nas classes menos abastadas (PNAD, 2013), os negros (pretos e pardos) são aqueles que mais apresentam dificuldades para acesso ao ensino superior público no Brasil. Nota-se que, em 2012, mais de $80 \%$ das matrículas feitas no ensino fundamental e médio se deram na rede pública de ensino, ao passo que $75 \%$ dos que ingressaram em universidades públicas neste ano eram egressos do ensino privado. Pode-se argumentar que estando os negros, em sua maioria, em classes menos abastadas, são eles maioria também entre os matriculados no ensino básico público. Nesse caso, como argumenta Neves (2012), os negros seriam duplamente discriminados no Brasil: dada a baixa qualidade do ensino básico recebido, esse grupo teria acesso limitado ao ensino superior; e com baixo capital econômico não disporiam de recursos para acessar instituições de ensino privadas. Tal acúmulo de desvantagens, por sua vez, interferiria negativamente em sua inserção no mercado de trabalho.

É importante salientar que, nas últimas duas décadas, o acesso ao ensino superior no Brasil sofreu significativa expansão. Clarissa Baeta Neves nos mostra que, nos anos 1990, os estudantes no ensino superior brasileiro somavam 1,5 milhões. Nos anos 2000, esse número quase dobrou, subindo para 2,7 milhões de estudantes. Dados de 2011 comprovam expansão ainda mais notável, apontando para um total de 6,4 milhões de estudantes matriculados no ensino superior. No entanto, não somente esse número não cresceu em proporção "à dimensão e às expectativas da população brasileira”, como prevalecem ainda desafios e problemas a serem superados quando se pensa em democratização do ensino superior (Neves, 2012, p. 2). As desigualdades sociais no acesso e permanência a este ensino consistem em um dos maiores desafios a serem enfrentados no país.

Segundo Neves (2012), a expansão das vagas no ensino superior brasileiro, sobretudo a partir de 2005 - quando políticas de inclusão começaram a ser implantadas nesse nível de ensino -, veio acompanhada de uma mudança na composição social dos alunos. Entretanto, a socióloga ressalta que ainda há marcante desigualdade étnico-racial e de renda no acesso a este nível de ensino no país - sendo os jovens brancos de classes mais abastadas, na faixa de 18 a 24 anos de idade, aqueles que ocupam a maior parte das vagas do ensino superior público e privado no Brasil. Podemos comprovar esse fato lançando mão de dados recentes da PNAD. Em 2012, 66,6\% dos brancos na faixa de 18 a 24 anos de idade cursavam o ensino superior, ${ }^{5}$ contra $37,4 \%$ dos negros na mesma faixa etária. Um percentual maior de negros nessa faixa, 44,2\%, encontrava-se ainda cursando o ensino médio e outros 9\%, o ensino fundamental. Esses dados expressam não somente a maior dificuldade do negro em acessar o ensino superior, mas a persistente defasagem série-idade que acompanha esse grupo, atuando como uma desvantagem a mais em sua inserção no mercado de trabalho. Não se pode perder de vista, porém, que vem aumentando, na última década, o ingresso de jovens das camadas mais baixas na universidade, sobretudo naquelas privadas, através do Programa Universidade para Todos (ProUni). Nessa mesma linha, pode-se dizer também que vem aumentando a presença de estudantes pretos e pardos no ensino superior, especialmente em razão da implantação de políticas de inclusão social como o já citado ProUni, o Programa de Apoio a Planos de Reestruturação e Expansão das Universidades Federais (REUNI) e as políticas de Ação Afirmativa, que mais diretamente interessam a este artigo.

A correlação entre acesso desigual a oportunidades educacionais e inserção desigual no mercado de trabalho fica clara no estudo de Carlos Antônio Ribeiro (2009) sobre as desigualdades de oportunidades educacionais no Brasil, quando o sociólogo conclui 
que a educação formal é uma das mais importantes vias para a mobilidade social e que o alcance de ocupações de prestígio no mercado exige, antes, qualificação educacional. Ao fazer um recorte por classe e raça, Ribeiro observou que ambas as variáveis exercem forte impacto nas chances de se completar as transições escolares. Embora argumente que a origem de classe exerça maior efeito do que a raça sobre as chances dos indivíduos de fazerem as transições, Ribeiro reconhece que nos níveis mais altos da transição educacional - ingresso e conclusão do ensino superior - o efeito da raça aumenta, enquanto o da classe diminui. Ou seja, quanto mais se sobe na hierarquia socioeconômica, mais importante se torna a variável raça para compreensão das desigualdades de oportunidades educacionais. Nesse sentido, Ribeiro refuta a hipótese largamente aceita na sociedade brasileira de que a desigualdade racial é apenas um reflexo das desigualdades socioeconômicas, seguindo na mesma linha de Hasenbalg (1979) e Hasenbalg e Silva (2003).

Todos esses fatores juntos contribuem para compor o ciclo cumulativo de desvantagens que envolve a inserção desigual do negro na sociedade brasileira e a "durabilidade" dessas relações desiguais. A associação entre baixa origem social, baixa escolaridade/limitado acesso ao ensino superior e características fenotípicas demarcadas atuam como desvantagens no acesso a melhores e mais rentáveis ocupações. $\mathrm{O}$ acesso à educação de baixa qualidade também restringe seu acesso a uma série de ocupações, e mesmo quando portam diplomas de ensino superior, estes advêm de instituições privadas, que, como aponta Barbosa (2014), contam com menor aceitação social no mercado.

Fundamentando-se em dados como os que apresentamos até então, vários autores, como Paixão et al. (2011), Heringer (2004), Heringer e De Paula (2009), Silvério (2002), Machado (2010), Guimarães (2012), Paiva e Almeida (2010) e Paiva (2013), para citar alguns, começaram a refletir sobre a importância da implantação de políticas estratégicas para inclusão dos negros (pretos e pardos) no ensino superior, bem como em outras esferas como a do mercado. O pano de fundo da argumentação desses autores, de modo geral, é o de que os negros têm chances limitadas de acesso ao ensino superior e aos cargos de maior prestígio e rentabilidade na estrutura ocupacional brasileira, não somente em razão de desvantagens socioeconômicas, mas também em função da permanência, na sociedade, do racismo e da discriminação racial. ${ }^{6}$ A adesão à implantação de políticas de Ação Afirmativa raciais, nesse sentido, apresenta-se como consequência dessa reflexão.

\section{As cotas raciais no meio acadêmico e na percepção dos entrevistados}

O debate sobre políticas de Ação Afirmativa teve início em meados dos anos 90 e ganhou força na esfera pública brasileira nos anos 2000, a partir da implementação - na Universidade do Estado do Rio de Janeiro (UERJ), Universidade Estadual do Norte Fluminense Darcy Ribeiro (UENF) e Universidade do Estado da Bahia (UNEB) - de sistemas de cotas para egressos de escolas públicas, negros, indígenas e deficientes físicos (Heringer, 2004; Paiva, 2013). A partir de 2004, com a adoção das cotas raciais pela UnB, o debate sobre tais políticas se intensificou, tanto no meio acadêmico quanto na sociedade civil como um todo. Se, por um lado, o debate deixa transparecer um relativo consenso sobre a existência de desigualdades entre brancos e negros, por outro, quando o assunto volta-se para as formas de enfrentamento dessas desigualdades, o debate aflora e iluminam-se dois discursos, claramente opostos, que apoiam ou rechaçam a necessidade e eficácia da adoção de políticas de ação afirmativa focalizadas como medidas para superar as desigualdades raciais, o racismo e a discriminação racial. Um dos discursos enfoca a necessidade de políticas racialmente focalizadas para promoção da equidade e inclusão de negros no ensino superior; o outro defende a importância de se manterem políticas universalistas que, ao invés de discriminar positivamente os negros, invistam em formas de enfrentamento que privilegiem a melhoria da educação básica, de modo a nivelar as condições de acesso dos candidatos ao ensino superior (Maio; Santos, 2005).

De maneira geral, podemos notar que o discurso contrário à implementação das AA raciais aparece fundamentado na chamada tradição de mestiçagem, na defesa da mistura como elemento constitutivo da identidade nacional. Os defensores dessa perspectiva argumentam que a implantação das cotas traz como consequência a racialização da sociedade brasileira, transformando-a em algo que ela não é: bicolor. Ao invés de combater, as cotas criariam um racismo que não existe no país e, além disso, seriam ineficientes para atacar as desigualdades entre brancos e negros, tendo em vista que estas provêm de desigualdades socioeconômicas e da educação de baixa qualidade que acessam (Fry et al., 2007; Fry; Maggie, 2004; Maggie; Fry, 2004; Maio; Santos, 2005). Pode-se dizer que esses autores defendem a manutenção de políticas universalistas ao invés da adoção de políticas racialmente focalizadas. Em outras palavras, o foco desse

6. De acordo com Silva e Reis (2011), há diferenças entre discriminação racial e racismo. Discriminação racial é quando há uma ativa exclusão de negros dos recursos e instituições, ao passo que racismo indica que a estrutura social é racializada comportando os brancos no topo de sua hierarquia. 
discurso sobre as cotas raciais encontra-se na defesa da igualdade formal, e não substantiva, no acesso a direitos. Os críticos da adoção das ações afirmativas raciais sustentam ainda que elas ferem o mérito no ingresso ao ensino superior e que propiciarão uma queda na qualidade do ensino nas universidades.

$\mathrm{O}$ discurso em favor das ações afirmativas raciais, por seu turno, expressa o reconhecimento das desigualdades socioeconômicas entre brancos e negros, acrescentando também o reconhecimento do racismo e da discriminação racial como categorias importantes para compreensão das relações desiguais que se estabelecem entre estes grupos, na sociedade brasileira (Contins, 2004; Paiva; Almeida, 2010; Silvério, 2002). Esse discurso reúne autores que defendem a importância da implementação das cotas raciais como forma de: reparar indivíduos e grupos historicamente subordinados e discriminados; favorecer a diversidade cultural e racial nas universidades; promover o fortalecimento da identidade negra, buscando reverter a autoimagem desfavorável que os acompanha; fomentar a igualdade de oportunidades educacionais e a democratização do ensino superior; combater a institucionalização das desigualdades no acesso a direitos; e acelerar o processo de formação dos futuros profissionais negros no Brasil etc. (Paiva, 2013).

O debate sobre Ação Afirmativa suscitou também o desenvolvimento de pesquisas para apreender a opinião dos brasileiros sobre as tais políticas que vinham causando tanta polêmica dentro e fora do meio acadêmico. Como informam Feres Jr. e Campos (2013), dois grandes institutos de pesquisa, o Datafolha e o Ibope, concluíram que parte significativa da população é favorável à adoção de políticas de ação afirmativa para negros: $51 \%$ da população (Datafolha), 62\% (Ibope). A pesquisa Datafolha (2008), no entanto, ressalta uma tendência à diminuição da aprovação das cotas raciais conforme aumenta o grau de escolaridade dos indivíduos e sua renda familiar. Além de negros - grupo-alvo das AA raciais, portanto -, nossos entrevistados possuem ensino superior completo e ocupam posições de prestígio na estrutura ocupacional da cidade do Rio de Janeiro. Seu grau de escolaridade e posição socioeconômica, no entanto, não os levam, em maioria, a desaprovar a adoção de políticas de cotas para negros no ensino superior.

A análise das entrevistas com profissionais negros de classe média do Rio de Janeiro nos mostra dados relativamente coincidentes com os apresentados para a população brasileira, uma vez que cerca de metade dos casos selecionados (41) demonstrou ser favorável à adoção das cotas raciais. Um número menor (26) identificou-se como contrário a tal política e outros 10 entrevistados mostraram-se ambíguos em suas opiniões, ora argumentando a favor, ora contra as cotas raciais. ${ }^{7}$

De modo geral, pode-se observar que as percepções dos entrevistados sobre as AA raciais apontam para repertórios muito próximos àqueles utilizados na defesa ou recusa da implementação de tais políticas nas universidades públicas brasileiras. Além disso, trazem um dado novo ao debate, que diz respeito ao receio de muitos de nossos entrevistados de que o negro seja visto como inferior e incapaz por precisar de cotas para ingressar em universidades. Esse medo, no entanto, aparece apenas nos discursos daqueles que se mostram contrários às cotas raciais, o que veremos adiante.

Vale ressaltar, desde já, que não observamos diferenças expressivas nas percepções dos entrevistados, segundo o sexo ou identificação racial. Como foi dito no início do artigo, a maioria dos respondentes se autodefiniu como negros (64) e isso não implicou - ao menos em nossa sequência de casos - diferenças significativas quanto à sua percepção sobre as cotas raciais. O mesmo pode ser dito com relação aos homens e mulheres da pesquisa, não tendo sido observada nenhuma tendência em suas percepções segundo o sexo.

Com relação aos entrevistados que se posicionaram contra as cotas raciais (26), observamos que a maioria deles se opõe à adoção de políticas focalizadas para quaisquer grupos sociais, inclusive, e sobretudo, os negros. E apenas seis desses entrevistados concebem a adoção de políticas sociais que possam vir a beneficiar estudantes de baixa origem social e/ ou deficientes físicos. A quase totalidade desses profissionais defende a manutenção de políticas universais, cujo foco deve estar na melhoria da qualidade da educação básica e não na criação de políticas de ação afirmativa.

Na minha opinião é um trabalho de longo prazo que passa pelo fortalecimento do ensino público desde a base; eu tenho que fazer essas pessoas terem acesso a um ensino fundamental de qualidade para que esse cara entre no ensino médio com uma base, reforce a base do ensino médio e, aí sim, tenha acesso à universidade. (Homem, Negro, Economista) ${ }^{8}$

Então, é óbvio que isso tem que começar da base e não abrir exceções e cotas pros "coitadinhos afrodescendentes”. (Mulher, Preta-Negra, Guia Turístico)

A defesa da igualdade na competição, seguida da valorização do esforço pessoal e do mérito permeiam

7. Três entrevistados não se pronunciaram a respeito do tema.

8. A autoria das citações apresentadas neste artigo está expressa a partir do sexo, autoclassificação racial e profissão do entrevistado. 
seus discursos e justificativas para investimento na educação básica, além de embasarem suas críticas ao tratamento especial de uma parcela da população em detrimento da outra.

Eu acho assim, se você tem inteligência, tem vontade, tem esforço, você tem o mesmo, nada me diferencia de outra pessoa daqui... Então eu vou estudar e vou conseguir. (Mulher, Mulata, Médica)

Além disso, esse argumento reforça a ideia de que o acesso pelas cotas não resolve o problema do negro. Uma vez na universidade, ele não conseguirá acompanhar os demais alunos que entraram por mérito e não conseguirá concluir o curso, tornando, portanto, a política de cotas ineficiente. Por seu baixo capital cultural - em razão da baixa qualidade do ensino básico acessado -, teriam dificuldades para acompanhar os demais alunos. Esse fato, associado ao seu baixo capital econômico - falta de meios para financiar transporte, alimentação, livros etc. -, diminuiria fortemente suas chances de sucesso no percurso universitário.

Eu preciso ter os caras em igualdade de competição para jogar o mesmo jogo... O que o sistema de cotas faz? Abre uma brecha pra esse cara que se preparou mal pra ele entrar na universidade, esse cara entra; mas não se mantém porque quando chegar lá o cara não acompanha o nível de exigência... (Homem, Negro, Economista)

Para esse grupo de entrevistados (26), o problema do negro não tem origem racial, mas socioeconômica e, portanto, se forem dadas oportunidades educacionais igualitárias, acompanhadas de esforço individual do negro, o problema da desigualdade entre negros e brancos no acesso à universidade estará resolvido.

Eu acho que o problema não é a cor e sim a condição que a grande maioria dos negros no Brasil estão submetidos, uma situação de pobreza, de pouco acesso ao estudo. (Mulher, n-i, ${ }^{9}$ Enfermeira)

A desigualdade entre negros e brancos, vista sob a chave da classe e não da raça, caminha junto com o argumento de que a adoção das cotas acabaria despertando o racismo e a discriminação na sociedade. Subjaz a esse argumento a ideia de que o racismo e a discriminação não permeariam nossas relações de sociabilidade, marcadas pela mistura, não tendo efeito, portanto, sobre as oportunidades sociais dos negros.

... a gente vai fazer a coisa inversa... você pode tá correndo o risco de despertar a discriminação nisso [com a adoção das cotas raciais]. (Mulher, Negra, Funcionária Pública)

... por isso eu sou contra esta cota [racial] criada no Brasil, eu acho que isso é uma forma de racismo indireto. (Homem, Negro, Advogado)

$\mathrm{Na}$ percepção desses entrevistados (26), além de favorecer o racismo e a discriminação racial, e de ferir o princípio da meritocracia no acesso ao ensino superior, a adoção das AA raciais teria ainda um efeito deletério para a imagem da população negra: as cotas reforçariam a imagem do negro como aquele que precisa de esmola, como coitadinho, inferior, incapaz $\mathrm{e}$ sem competência para entrar na universidade, já que seu ingresso através das cotas não ocorreria por mérito próprio.

... porque você não entrou pelo seu mérito você está sinalizando que você é uma pessoa inteligente? Não. (Homem, Pardo-Mulato, Economista)

Você quando faz segregação de vaga na universidade pro negro, você tá chamando ele de quê? Incompetente, não é isso? Por quê?, o negro não pode estudar? (Homem, Moreno, Engenheiro)

A sociedade vê o negro como uma pessoa incapaz. Isso me preocupa. "Você não é capaz de passar em tal lugar, eu boto você lá”. (Homem, Negro, Professor)

Essa imagem de inferioridade associada ao receio de que os cotistas venham a ficar marcados pelo favor recebido atravessam os discursos dos profissionais negros entrevistados (26) e demonstram o quanto o tema da discriminação e a própria imagem de inferioridade que os rodeia permeiam seus discursos e moldam seus medos com relação ao futuro. Em outras palavras, não é possível, para esses entrevistados, conceber uma política que se propõe a enfrentar o racismo, a desigualdade e a discriminação raciais através da própria discriminação do negro. Depreende-se de suas percepções o medo de que a adoção das cotas venha, no futuro, reforçar a ideia de inferioridade e incapacidade que historicamente foi associada à imagem do negro.

Eu não quero que meus filhos passem pelos corredores [das universidades] e sejam criticados pela cor deles, eles estão ali pela competência. (Mulher, Negra, Professora)

... ou seja, a gente gera uma possibilidade de uma geração que passe por cotas, que seja vista como incompetente, que tá ali por favores... A questão da inferioridade, né? (Homem, Negro, Funcionário Público) 
É importante não perdermos de vista que todos esses profissionais (26) que se posicionaram contrários à adoção das AA raciais passaram pelo ensino superior e ingressaram nele sem o aporte das cotas. Além disso, suas trajetórias de mobilidade social justificam seu apego à ideia de esforço, competência, capacidade e mérito. O orgulho que expressam por ocuparem as posições de prestígio que ocupam e por as terem alcançado por mérito próprio poderia ser um elemento para a explicação de sua posição contrária às cotas, mas não o determinante, visto que o mesmo perfil de mobilidade social é observado entre os demais profissionais selecionados em nossa pesquisa que são favoráveis às cotas raciais (41) e aqueles que ainda se mostram ambíguos em suas posições (10).

Vale destacar que alguns profissionais, além de criticarem o sistema de cotas raciais, criticaram mais especificamente a forma de seleção dos cotistas. O argumento que embasa essa discussão é o de que, por ser o Brasil um país marcado pela mistura, torna-se difícil saber quem é negro e quem não o é. Sendo assim, o sistema de cotas permitiria "aberrações" como a identificação de um estudante como negro - e apto a acessar a universidade através de cotas - e outro, seu irmão gêmeo, como branco, inapto, portanto, a disputar uma vaga de cotista.

Eu não acredito que a metodologia utilizada tanto nos Estados Unidos como na África seja a mais... a ideal pro Brasil, por causa da mistura, da peculiaridade do Brasil. (Homem, Negro, Funcionário Público)

Diferentemente do que ocorre entre os contrários às cotas, aqueles que as defendem (41) justificam sua adoção em razão da inexistência de igualdade de oportunidades sociais e educacionais entre brancos e negros, no Brasil. Não existindo igualdade de oportunidades, o "ponto de partida" de brancos e negros seria desigualmente distribuído, tornando impossível configurar o acesso ao ensino superior como meritocrático, justo e igual para todos. A percepção desses entrevistados é a de que não dá pra tratar desiguais como iguais, isso sim seria uma forma de injustiça.

Agora, uma pessoa que não tem o mesmo acesso à educação que você teve, concorrer com ela? Isso é injustiça, o que tá sendo feito hoje é justiça. É igual pegar o Ipatinga no fim do campeonato: é moleza! (Homem, Negro, Engenheiro)

Nesse sentido, o sistema de cotas raciais seria apontado como justo e uma forma de, a longo prazo, as próximas gerações de negros poderem efetivamente competir com os brancos em posição de igualdade.
Hoje eu posso, mas amanhã meus netos, bisnetos não precisarão mais de cotas. Hoje, nós negros, pobres e carentes não temos condições de entrar numa universidade, mas, futuramente, outros terão. Pra mim isso é uma lei ordinária, uma lei imediata, porque uma pessoa que se forma hoje em Direito, uma menina negra, ou pobre, entrou hoje na UFF, com cota, pra Direito, os filhos dela, com certeza, não precisarão de cotas pra entrar. (Mulher, Negra, Funcionária Pública)

Reside neste argumento a ideia de que as cotas raciais foram criadas para promoção da igualdade de oportunidades entre negros e brancos. Sendo assim, ao fim de algumas gerações tal política já terá cumprido seu objetivo principal, o de formar uma elite negra, cujos filhos poderão competir com os brancos em efetiva igualdade de oportunidades, sem, portanto, a necessidade de recorrer a ações afirmativas para isso.

Diante de um cenário onde a oportunidade não é igual pra todo mundo, o vestibular é criticado como critério de seleção e o princípio da meritocracia percebido como algo que deve ser avaliado no decorrer do curso de graduação e em sua conclusão, mas não na entrada, quando a competição pelas vagas se dá de forma desigual.

O maior problema não é entrar na faculdade, o problema é se manter lá dentro. (Mulher, Parda, Assistente Social)

Além de possibilitar que os filhos e netos dos atuais cotistas não venham a precisar de cotas no futuro, a entrada de mais negros no ensino superior por meio das cotas aceleraria a formação de profissionais negros mais qualificados. Isso atuaria não somente nas oportunidades sociais de seus filhos e netos e na formação de uma elite negra no país, mas na própria modificação da imagem de inferioridade social que o negro carrega, sempre associada a posições socioeconômicas inferiores e a ocupações de menor qualificação e prestígio social - como já apontaram Guimarães (2012) e Soares (2000).

... mas para que, daqui a 15, 20 anos, que é o período mais ou menos que essas pessoas serão formadas... aí vão ter mais negros aí... e quando ele olhar o negro vestido de branco, ele não vai olhar a cor, ele não vai pensar que é um pai de santo, ele vai pensar que pode ser um médico. Quando ele ver um negro de terno, ele não vai pensar que é um segurança, ele vai pensar que pode ser um advogado.... por esse prisma, realmente, a política de cotas valeria. (Homem, Negro, Advogado) 
No caso das próprias cotas, o fato de você entrar numa universidade hoje em dia, você vê um monte de pontos pretos no campus que não estão de vassoura na mão... deve dar aos poucos... uma sensação diferente da época que eu era o único na turma. (Homem, Negro, Economista)

No jargão do Movimento Negro, tal aceleração da formação de novos quadros negros na sociedade permitiria o empoderamento dos negros, isto é, o fortalecimento de uma identidade coletiva negra, de seu reconhecimento social como igual, da própria valorização de seus traços fenotípicos e culturais, além da inversão da imagem inferiorizada e estereotipada que o negro ocupa no imaginário social.

Mas quem é negro sabe daquele olhar que eu te falei do porteiro; sabe daquela professora que cuida melhor daquela garotinha lourinha de bochechinhas rosadas, dá mais atenção pra ela; sabe do colega que quando você se desentende te chama de "macaco", de "cabelo de Bombril", quer dizer, te despreza pela sua aparência. Então, o Brasil precisa dizer pros seus filhos negros: "Eu quero você assim, é você que eu quero! Você com esse cabelo, com essa cor, com esse nariz". Entende? É trocar o "Você não" por "Você sim”. (Mulher, Negra, Jornalista)

Alguns entrevistados chamaram a atenção para o fato de que, sem o acesso às cotas, a maioria dos negros que hoje ingressam no ensino superior não o fariam. Primeiro em razão de déficits em sua formação educacional pregressa, o que os impediria de ingressar em uma universidade pública; segundo, por sua baixa origem social, dificultando o acesso e a permanência em instituições privadas - configurando o cenário de dupla discriminação sofrida pelos negros, já abordados por Neves (2012) e Guimarães (2012).

... pelo menos você está inserindo mais pessoas negras na faculdade, no ensino superior, pessoas que, de repente, não teriam chance de pagar a faculdade ou de fazer uma pública também. (Mulher, Negra, Economista)

Não obstante defendam a adoção das cotas raciais (41), a maioria desses entrevistados aponta que, somado a este recurso para inclusão dos negros, o Estado deveria focar na melhoria do ensino básico público para que as gerações futuras tenham chance de competir em igualdade de condições e possam prescindir do sistema de cotas. Seguindo nessa mesma linha, nossos entrevistados chamam a atenção para o caráter temporário das cotas, argumentando que as mesmas devem deixar de existir tão logo existam condições igualitárias de competição entre brancos e negros.
Eu acho que cotas é uma coisa temporária. Junto com isso tem que vir um ensino público legal. Chega um dia em que todo mundo tá em pé de igualdade... (Mulher, Negra, Médica)

As cotas também são vistas pelos entrevistados como forma de reparação pelo passado de escravidão. A ideia é que o Brasil, em decorrência da escravidão, teria uma dívida social com os negros e as cotas atuaram como "um mecanismo de inclusão" desse grupo historicamente discriminado.

Eu acho que tem que ter sim [cotas raciais], até por um passado que a gente não pode jogar fora. Se a sociedade chegar e falar assim: "Eu errei, eu fiz de um homem um animal de amarrar uma corrente no pescoço"; e falar: "Você é meu escravo por causa da sua cor". E até hoje há o preconceito por causa disso, por causa de uma sociedade que tinha dinheiro e botou uma corrente no pescoço de um monte de negros e falou: "Você é meu e eu te vendo". Chegar e falar: "Como eu errei no passado, como eu fiz um monte de besteira e, como consequência disso, olha o efeito que deu: nas universidades federais não tem nenhum [negro]; no Santo Agostinho não tem nenhum [negro]". (Homem, Negro, Contador)

Associado a este discurso está o de que, mesmo com o fim da escravidão, não abolimos o racismo e a discriminação contra os negros. Desta forma, a cota racial viria não somente como forma de compensar o negro por tal herança, mas também para superar o racismo, a discriminação e as desigualdades raciais que persistem na sociedade brasileira e funcionam como barreiras à mobilidade social dos negros.

Nessa mesma linha, a ideia de que as cotas fomentariam o racismo na sociedade é tida pelos profissionais como uma inversão da realidade.

Então, no caso das cotas, quando vão estabelecer cotas que permitam aos negros atingir a universidade de uma maneira diferenciada, então o pessoal corre pra dizer que isso é um preconceito ao contrário. Isso é dizer que eles não são iguais, não é isso? Mas eles não são iguais, socialmente não são iguais, tanto é que a gente vê que a grande maioria de negros e mulatos não ocupa nenhum posto de relevância [na sociedade]. (Homem, Negro, Advogado)

[...] as pessoas falam enraivecidas que isso vai acirrar o racismo... como vai aumentar uma coisa que sempre existiu, que sempre feriu, machucou, devastou emocionalmente as pessoas? Vai aumentar nada, isso vai dar mais força pra essas pessoas lutarem. E existem negros que afirmam: "Eu não quero isso porque vai me diminuir, por isso e aquilo". Porque é tão incutido 
na cabeça das pessoas que os negros são diminuídos que até os negros entendem as cotas como sendo algo que vai diminuí-los... (Mulher, Negra, Psicóloga)

Há um consenso entre os entrevistados sobre o fato de os negros pertencerem, em sua maioria, aos estratos mais baixos da sociedade e isso representar uma desvantagem na competição por uma vaga no ensino superior. No entanto, é também enfatizado por alguns respondentes que há, no Brasil, um estoque enorme de pobreza que tem origem racial, pelo tamanho da exclusão que foi imposta aos negros brasileiros. Nesse sentido, o problema do negro não é visto por esses entrevistados como apenas decorrente de sua condição de pobreza, como defendem os críticos das cotas, mas por questões ligadas ao racismo e à discriminação ainda existentes.

Não tenho essa coisa de "ah, as cotas têm que ser econômicas pra tentar fugir de um problema que tá na nossa cara”. Não tem que fugir, tem que ser racial sim. A gente tem anos de segregação racial no Brasil. (Mulher, Negra, Jornalista)

Um tema muito em voga no discurso acadêmico favorável às cotas também apareceu relatado por alguns de nossos entrevistados, aquele ligado à promoção da diversidade cultural e racial na universidade. Para os que abordaram o tema, as cotas são importantes para que a universidade reflita, de alguma maneira, a população brasileira, coisa que não acontece na atualidade, visto que nossas universidades são brancas.

Por fim, os entrevistados (41) não somente atestaram a existência de desigualdades entre brancos e negros, como reconheceram a existência do racismo, da discriminação e do preconceito raciais na sociedade. Um dos profissionais entrevistados recorreu à ideia de incômodo para elucidar a existência de preconceito e discriminação no país. Tal incômodo provocado pelos negros justificaria, inclusive, a maior recusa às políticas focalizadas para negros, quando comparadas àquelas voltadas para deficientes físicos, indígenas ou estudantes de baixa origem social - um ponto já apontado por Ângela Paiva (2013) em seus estudos sobre políticas de Ação Afirmativa nas universidades.

E quando surgem as cotas, só se importam com a cota dos negros e ninguém fala da cota dos índios, da cota dos oriundos da escola pública e nem dos deficientes; mas os negros incomodam... que nós reivindiquemos as cotas, incomoda. (Mulher, Negra, Psicóloga)

Por razões como essas, tanto as cotas raciais quanto o próprio debate que elas vêm despertando na sociedade são percebidos pelos entrevistados (41) como importantes e defensáveis. Para eles, a questão da diferença social, das desigualdades entre negros e brancos e o próprio questionamento sobre se temos ou não racismo e discriminação no Brasil se tornaram assuntos públicos devido à adoção das cotas, a partir da última década. E a publicização desse debate, associada à maior formação de profissionais negros, seria especialmente importante para o enfrentamento do racismo.

... um dos caminhos [para o enfrentamento] do racismo é a questão da visibilidade, né? É o fato de você conseguir formar uma geração de profissionais de nível superior negros, eu acho que isso é de uma importância vital. (Homem, Negro, Jornalista)

Quanto aos entrevistados que se mostraram ambíguos em suas respostas (10), pode-se dizer que seus discursos apontam, simultaneamente, os prós e os contras da medida. Além disso, eles recorrem aos mesmos repertórios utilizados - e apresentados anteriormente - por aqueles que criticaram e aqueles que defenderam a adoção das AA raciais. De modo geral, embora não concordem com a adoção de políticas focalizadas para negros, reconhecem a existência de desigualdades e discriminação raciais, assim como a importância de se criarem políticas para inclusão do negro na sociedade. Por outro lado, a rejeição desse grupo às políticas de ação afirmativa raciais se concentrou em dois motivos principais: o primeiro diz respeito à mistura que nos caracterizaria, o segundo, ao fato de as desigualdades que assolam os negros se deverem, particularmente, à sua baixa origem social. Em outras palavras, para esse grupo de entrevistados, o critério de seleção por cotas raciais seria equivocado, visto ser a sociedade brasileira misturada. O fato de sermos misturados tornaria difícil a definição de quem é negro e quem não é nesse país. Além disso, não só os negros não entram nas universidades, mas todos os pobres, o que justifica sua preferência pelas cotas sociais em detrimento das raciais.

\section{Considerações finais}

$\mathrm{O}$ artigo em questão pretendeu analisar as percepções de 80 profissionais negros de camadas médias, no Rio Janeiro, sobre as cotas raciais nas universidades públicas brasileiras. Por serem negros de classe média com alto grau de escolaridade e com prestigiosas ocupações no mercado de trabalho, suas percepções sobre uma política que visa incluir a população negra no ensino superior se mostram relevantes para pensarmos as relações raciais brasileiras. Apresentamos ao longo deste trabalho pesquisas que apontam para 
a persistente desigualdade racial no Brasil e que chamam a atenção para os efeitos da raça sobre as oportunidades educacionais dos indivíduos. Falar sobre os efeitos da raça nos leva a endossar o argumento de que o racismo, o preconceito e a discriminação raciais são categorias relevantes para pensarmos o quadro das desigualdades raciais brasileiras, as fontes de sua durabilidade, assim como as formas mais adequadas para inclusão dos negros na sociedade e que, portanto, não deve estar subsumida à questão da classe.

Nota-se que o reconhecimento das desigualdades entre brancos e negros no Brasil é um fato objetivo para grande parte da população brasileira - como demonstram surveys como o Datafolha (2008), por exemplo, e também os discursos dos 80 entrevistados analisados neste artigo. De modo geral, o que os diferencia, contudo, não é o reconhecimento ou não das desigualdades, mas a importância dada à questão da raça como fonte explicativa dessas desigualdades. Nossa seleção de casos se divide entre aqueles que veem a questão das desigualdades de oportunidades que limitam a mobilidade social dos negros como efeito (também) da raça e aqueles que a compreendem como efeito (apenas) da classe. Estes últimos tendem a se posicionar contrariamente à adoção de políticas focalizadas para inclusão do negro no ensino superior, e a preferir o desenvolvimento de políticas universais como aquelas que investem no ensino básico público. Aqueles, por sua vez, parecem encontrar no reconhecimento da discriminação e do racismo as fontes para a durabilidade das desigualdades raciais, e nas cotas, a forma mais adequada de enfrentamento desses elementos, a curto prazo. Quanto aos entrevistados que se mostraram ambíguos em suas percepções sobre as cotas raciais, observa-se que reconhecem a existência da desigualdade e discriminação raciais no Brasil e a necessidade de seu enfrentamento, mas titubeiam em seu apoio à adoção de políticas focalizadas para negros, em especial, porque consideram complicado, em um país caracterizado pela mistura, definir o público-alvo "negro" de tais políticas. Além disso, argumentam que os negros são maioria nas classes menos abastadas da sociedade, sendo difícil aferir a que se deve a persistência das desigualdades e discriminações, se a efeitos da classe ou da raça. Este último argumento, inclusive, é o que leva alguns profissionais entrevistados a apoiarem a adoção de políticas de cotas sociais ao invés das raciais.
Outros aspectos que demarcam distinções nas percepções dos entrevistados sobre as cotas raciais dizem respeito à imagem do negro que as cotas podem vir a criar e à ideia da democracia racial, com sua consequente valorização da mistura étnico-racial. Percebemos que os argumentos mais recorrentes para demonstrar oposição às cotas raciais aparecem ligados ao receio dos entrevistados de que os negros, por serem objeto de tais políticas de inclusão, venham a ser percebidos como inferiores e incapazes de competir com os brancos em igualdade de condições. Esses mesmos entrevistados percebem a mistura étnico-racial como característica peculiar da sociedade brasileira, o que, por sua vez, tornaria impossível classificar os indivíduos por sua raça. Esse tipo de classificação, portanto, ao invés de incluir, resultaria em segregação, discriminação e preconceito contra os negros.

Observamos que os apoiadores das AA raciais não somente apontam essa medida como importante para inclusão dos negros no ensino superior, a curto prazo, mas também a consideram definitiva para a formação de uma futura elite negra, de um maior número de profissionais que ocuparão, no futuro próximo, posições prestigiosas na estrutura ocupacional brasileira - ainda racializada. A associação entre baixa qualidade educacional acessada, baixa origem social, características adscritivas ${ }^{10}$ e (auto)imagem inferiorizada do negro no imaginário social constrói as bases de apoio para medidas que acelerem a inserção do negro na sociedade, como as cotas raciais. A aposta é que, no futuro, possamos prescindir de tais políticas.

Por fim, vimos, ao longo do artigo, que as justificativas utilizadas pelos entrevistados para aderir ou rechaçar a implantação de políticas de cotas para negros se ajustaram perfeitamente aos dois discursos sobre as cotas predominantes no meio acadêmico brasileiro e na sociedade em geral. Apesar de não contarmos com uma amostra representativa da população, notamos que nossa seleção de casos, a despeito de ser composta somente por negros de classe média e com nível superior de escolaridade, recorre aos mesmos repertórios sociais que vigoram na sociedade em geral e no meio acadêmico, quando o assunto envolve as cotas raciais e, em última instância, os valores e identidades que atravessam as relações raciais brasileiras. Nesse sentido, esperamos poder contribuir com mais esses dados para o rico debate que vem se desenvolvendo na esfera pública e na academia brasileira nos últimos anos. 


\section{Referências}

BARBOSA, M. L. de O. O ensino superior no Brasil: credencial, mérito e os coronéis. In: (Org.). Ensino superior: expansão e democratização. Rio de Janeiro: 7 Letras, 2014.

CONTINS, M. Estratégias de combate à discriminação racial no contexto da educação universitária no Rio de Janeiro. In: PAIVA, A. R. (Org.). Ação afirmativa na universidade: reflexão sobre experiências concretas Brasil-Estados Unidos. Rio de Janeiro: Ed. PUC-Rio/ Desiderata, 2004.

DAFLON, V. T.; FERES JR., J.; CAMPOS, L. A. Ações afirmativas raciais no ensino superior público brasileiro: um panorama analítico. Cadernos de Pesquisa, São Paulo, v. 43, n. 148, jan./abr. 2013.

DATAFOLHA. Racismo confrontado. Folha de S. Paulo, 23 nov. 2008

FERES JR., J.; CAMPOS, L. A. O "discurso freyreano" sobre as cotas raciais: origem, difusão e decadência. In: PAIVA, A. R. (Org.). Ação afirmativa em questão: Brasil, Estados Unidos, África do Sul e França. Rio de Janeiro: Pallas, 2013.

FRY, P. et al. (Orgs.). Divisões perigosas: políticas raciais no Brasil contemporâneo. Rio de Janeiro: Civilização Brasileira, 2007.

FRY, P.; MAGGIE, Y. Cotas raciais: construindo um país dividido. Econômica, Rio de Janeiro, v. 6, n. 1, p. 153-161, jun. 2004.

GUIMARÃES, A. S. Classes, raça e democracia. São Paulo: Editora 34, 2012.

HASENBALG, C. A. Discriminação e desigualdades raciais no Brasil. Rio de Janeiro: Graal, 1979.

HASENBALG, C. A.; SILVA, N. do V. (Orgs.). Origens e destinos: desigualdades sociais ao longo da vida. Rio de Janeiro: Topbooks, 2003.

HERINGER, R. Ação afirmativa e promoção da igualdade racial no Brasil: o desafio da prática. In: PAIVA, A. R. (Org.). Ação afirmativa na universidade: reflexão sobre experiências concretas Brasil-Estados Unidos. Rio de Janeiro: Ed. PUC-Rio/Desiderata, 2004.

HERINGER, R.; DE PAULA, M. et al. (Orgs.). Caminhos convergentes: estado e sociedade na superação das desigualdades raciais no Brasil. Rio de Janeiro: ActionAid e HBS, 2009. v. 1.

LAMONT, M.; MIZRACHI, N. Ordinary people doing extraordinary things: responses to stigmatization in comparative perspective. Ethnic and Racial Studies (Print), v. 35, n. 3, p. 365-381, 2012.

MACHADO, E. A. A invenção das cotas: políticas de ação afirmativa e os estudantes universitários. In: PAIVA, A. R. (Org.). Entre dados e fatos: ação afirmativa nas universidades públicas. Rio de Janeiro: Ed. PUC-Rio/Pallas, 2010. MAGGIE, Y.; FRY, P. A reserva de vagas para negros nas universidades brasileiras. Estudos Avançados, v. 18, n. 50, 2004.

MAIO, M. C.; SANTOS, R. V. Política de cotas raciais, os "olhos da sociedade" e os usos da antroplogia: o caso do vestibular da Universidade de Brasília (UnB). Horizontes Antropológicos, Porto Alegre, ano 11, n. 23, p. 181-214, jan./jun. 2005.

NEVES, C. E. B. Ensino Superior no Brasil: expansão, diversificação e inclusão. Congresso da LASA (Associação de Estudos Latino-Americanos), São Francisco, Califórnia, maio, 2012.

PAIVA, A. R. Políticas públicas, mudanças e desafios no acesso ao ensino superior. In: ______. (Org.). Ação afirmativa em questão: Brasil, Estados Unidos, África do Sul e França. Rio de Janeiro: Pallas, 2013.

PAIVA, A. R.; ALMEIDA, L. C. de. Mudança no Campus: falam os gestores das universidades com Ação Afirmativa. In: PAIVA, A. R. (Org.). Entre dados e fatos: ação afirmativa nas universidades públicas. Rio de Janeiro: Ed. PUC-Rio/Pallas, 2010.

PAIXÃO, M.; ROSSETO, I.; MONTOVANELE, F.; CARVANO, L. Relatório anual das desigualdades raciais no Brasil: 2009-2010. Rio de Janeiro: Garamond, 2011.

PNAD. Pesquisa Nacional por Amostra de Domicílios. IBGE, 2003 e 2013

RIBEIRO, C. A. da C. Desigualdade de oportunidades no Brasil. Belo Horizonte: Argvmentvm, 2009.

SILVA, G. M. da. Folk conceptualizations of racism and antiracism in Brazil and South Africa. Ethnic and Racial Studies (Print), v. 35, n. 3, p. 506-522, 2012.

SILVA, G. M. da; REIS, E. P. Perceptions of racial discrimination among black professionals in Rio de Janeiro. Latin American Research Review, v. 46, n. 2, 2011.

The multiple dimensions of racial mixture in Rio de Janeiro, Brazil: from whitening to Brazilian negritude. Ethnic and Racial Studies (Print), v. 35, n. 3, p. 382-399, 2012.

SILVÉRIO, V. R. Ação afirmativa e o combate ao racismo institucional no Brasil. Cadernos de Pesquisa, n. 117, nov. 2002.

SMALL, M. L. How many cases do I need? On science and the logic of case selection in field-based research. Ethnography, v. 10, n. 5, 2009.

SOARES, S. O perfil da discriminação no mercado de trabalho: homens negros, mulheres brancas e mulheres negras. Texto para Discussão n. 769. Brasília: Instituto de Pesquisa Econômica Aplicada, 2000. 


\title{
The policy of racial quotas in Brazil according to the perception of black middle class in Rio de Janeiro
}

\begin{abstract}
The debate about the racial quotas in higher education has divided opinions in Brazil, featuring two well-marked speeches: one in favor of these policies, defending cultural diversity and democratization of higher education; the other in defense of maintaining universal policies, arguing that racial quotas hurt our tradition of miscegenation and foster the racialization of society. The aim of this paper is to contribute to the discussion of race relations in Brazil, from the analysis of the perception of black professional middle class in Rio de Janeiro on the adoption of such policies in higher education and their justifications to support or refuse them.
\end{abstract}

Key words: affirmative action, racial quotas, race relations, higher education, educational inequalities.

\section{La política de cuotas raciales en Brasil de acuerdo con la percepción de la clase media negra en Río de Janeiro}

\section{Resumen}

El debate acerca de la adopción de políticas de cuotas raciales en la educación superior ha dividido opiniones en Brasil y presenta dos discursos bien marcados: uno favorable a las cuotas, con defensa de la diversidad cultural y la democratización de la educación superior; y uno que se interpone en defensa del mantenimiento de las políticas universales, con el argumento de que la adopción de las cuotas raciales hiere nuestra tradición de mestizaje y fomenta la racialización de la sociedad. El objetivo de este trabajo es contribuir a la discusión de las relaciones raciales en Brasil, a partir del análisis de la percepción de profesionales negros de clase media en Río de Janeiro con respecto a la adopción de estas políticas en la educación superior y sus justificaciones para apoyarlas o rechazarlas. Utilizaré datos de estudios recientes sobre acciones afirmativas (AA) raciales en Brasil y entrevistas semiestructuradas con negros de clase media de Río de Janeiro.

Palabras clave: acción afirmativa, política de cuotas raciales, relaciones raciales, educación superior, desigualdades educativas.

Data de recebimento do artigo: 13/11/2014

Data de aprovação do artigo: 3/3/2015 